\title{
Value streams in microgrids: A literature review
}

\author{
Michael Stadler ${ }^{1,2, *}$, Gonçalo Cardoso ${ }^{1}$, Salman Mashayekh ${ }^{1}$, Thibault Forget ${ }^{1,3}$, \\ Nicholas DeForest ${ }^{1}$, Ankit Agarwal ${ }^{1,4}$, Anna Schönbein ${ }^{1,5}$
}

${ }^{1}$ Ernest Orlando Lawrence Berkeley National Laboratory, 1 Cyclotron Road, MS: 90-1121, Berkeley, California 94720, USA

${ }^{2}$ Center for Energy and innovative Technologies (CET), Doberggasse 9, 3681 Hofamt Priel, Austria

${ }^{3}$ MINES ParisTech, 60 Boulevard Saint-Michel, 75006 Paris, France

${ }^{4}$ University of California, Berkeley, California, USA

${ }^{5}$ University of Freiburg, Platz der Alten Synagoge, 79085 Freiburg, Germany

* Corresponding Author: mstadler@lbl.gov or mstadler@ cet.or.at, Tel.: +1.510.486.4929 or +43.(0) 664.7390.7185

\begin{abstract}
Microgrids are an increasingly common component of the evolving electricity grids with the potential to improve local reliability, reduce costs, and increase penetration rates for distributed renewable generation. The additional complexity of microgrids often leads to increased investment costs, creating a barrier for widespread adoption. These costs may result directly from specific needs for islanding detection, protection systems and power quality assurance that would otherwise be avoided in simpler system configurations. However, microgrids also facilitate additional value streams that may make up for their increased costs and improve the economic viability of microgrid deployment. This paper analyses the literature currently available on research relevant to value streams occurring in microgrids that may contribute to offset the increased investment costs. A review on research related to specific microgrid requirements is also presented.
\end{abstract}

Keywords: microgrid; planning; revenue; demand response; exports; net metering

\section{Introduction}

Understanding the process behind the design of a microgrid requires defining what a microgrid is. Decentralized energy systems are not new, nor is the concept of on-site generation, backup, or emergency systems. However, it was not until recently that the currently accepted concept of microgrid was clearly defined as a cluster of small sources, storage systems, and loads, which presents itself to the main grid as a single, flexible, and controllable entity [1], [2].

By introducing on-site generation, storage, and bidirectional power flow, microgrids can be seen as a valuable resource to the grid, while also being more independent from it. This creates the settings for flexible operation conditions, albeit at a cost: Microgrids are complex energy systems that require specific infrastructure, resource coordination, and information flows, as well as added protection and power quality assurance. Guaranteeing all of these conditions can potentially jeopardize the economic viability of microgrids, making it vital that design steps account for all different revenue streams, both direct and indirect, that result from microgrid deployment.

This paper conducts a review on research relevant to the economic analysis of microgrid design, including the technical challenges in microgrids that can potentially increase their economic burden. This is followed by review of potential revenue streams that can offset investments and business-as-usual costs, 
and how the state-of-the-art is addressing each of these monetization elements. The key value streams identified in this review are given below, with details of each value stream outlined in Section 3.

- Participation in Demand Response programs

- Export of on-site generation to the electricity grid

- Reduced costs due to added resiliency against outages and lost loads

- Participation in local microgrid energy markets

\section{Technical Requirements}

A cluster of interconnected loads and distributed energy resources (DER) does not qualify as a microgrid by itself unless several technical requirements are met, among which are the ability to operate in gridconnected and islanded mode, the ability to transit smoothly between the two modes with minimal load disruption under intentional and unintentional conditions, proper relaying and protection, and power quality assurance [3]-[5]. It is only when these requirements are met that a microgrid is effectively implemented and its benefits can be obtained.

\subsection{Islanding detection}

Fast islanding detection in microgrids is especially important, since the microgrid control method depends on the microgrid operation mode: being grid-connected or islanded. In the grid-connected mode, the microgrid frequency and the point of common coupling (PCC) voltage are dominantly determined by the main grid. Hence, DERs do not actively participate in voltage or frequency regulation and the main goal of the microgrid controller is to maximize the optimal use of DERs to support local objectives. In contrast, in the islanded mode the microgrid controller must carry out voltage and frequency regulation by controlling DER and load set-points [5], [6].

Authors in [5] and [7] review islanding detection methods in microgrids, and classify them into remote and local methods. Remote methods detect islanding through communication with the main grid and monitoring of the circuit breaker status. Local methods determine the operation mode based on measuring local variables such as voltage and frequency, and are further categorized as active and passive methods. While passive methods only measure local variables, active methods inject small disturbances into the microgrid and monitor their impact on local variables. Effectiveness of microgrid islanding methods can be measured and compared using performance indices such as non-detection zone, detection time, error detection ratio, and impact on power quality.

\subsection{Relaying and protection}

Current electrical distribution systems have been mostly designed and built for unidirectional power flow in radial networks towards distribution loads. The integration of DERs into distribution systems and microgrids changes this paradigm, and complicates the problem of distribution system protection, by changing the fault current levels, disrupting the previous protection coordination, changing fault current flow paths, and generating bidirectional fault power flows [8]. Proper protection of microgrids (downstream the PCC) is also a challenging task, since fault current magnitudes in the system depend on the microgrid operation mode, and may vary significantly between grid-connected and islanded modes. Moreover, the fault current magnitudes in the system, especially in the islanded mode, greatly depend on the types of DERs being connected during the fault occurrence, since directly-connected DERs contribute to short-circuit currents much more than inverter-based DERs [9]. 
Several papers in the literature review existing microgrid protection schemes [8], [10]-[13]. Mirsaeidi et. al. [11] divide microgrid protection schemes into the following categories: (a) adaptive protection schemes automatically adjust the microgrid protection rely settings when fault current levels significantly change due to a change in operation mode or changes in the types of connected DERs; (b) differential protection schemes protect a particular zone in the microgrid and will operate if the difference between the input and output currents into and from the zone exceeds a pre-determined threshold; (c) admittance protection schemes that use distance relays; (d) voltage-based protection schemes that rely on monitoring the voltage across different locations in the microgrid; (e) protection schemes that change the short-circuit levels in the network by utilizing fault current limiters or energy storage devices; and (f) protection schemes that use over-current protection relays. Moreover, the work presented in [12] divides protection coordination strategies in microgrids into (a) time-grading-based and (b) communication-based approaches.

\subsection{Power quality}

Harmonic contents and voltage unbalance are the two main power quality problems in microgrids [7], [14]. The presence of power electronic devices such as switch mode power supplies, variable frequency drives, and DER inverters in microgrids injects harmonic contents into the microgrid as well as the main grid. Significant harmonic currents can cause overheating, excessive transmission and component losses, malfunctioning of protection relays and tripping of circuit breakers, and communication errors [13]. Voltage imbalance in the network is mainly due to connecting unbalanced loads, and can negatively impact sensitive loads such as induction motors, power electronic converters, and variable frequency drives [14]. To protect both the microgrid and the main grid against these power quality problems, several codes and standards define acceptable thresholds for voltage unbalance and voltage/current harmonic distortion, e.g. [15], [16].

References [7], [10], [13] review some of the existing microgrid power quality enhancement methods in the literature. Even though these methods include a wide variety of flavors, they mainly rely on leveraging existing DER power electronic interfaces or utilizing active power filters. Some of the proposed methods are suppression of circular currents [17], use of active filters [18], [19], use of optimally controlled shunt and series inverters [20], [21], cooperative harmonic filtering [22], and injection of negative sequence voltage [23] or current [24] to compensate for voltage unbalance.

While determining the economic burden introduced by these requirements is highly dependent of the exact microgrid system configuration, it is clear that it poses a barrier to widespread microgrid deployment, and failing to understanding the full spectrum of microgrid revenue streams will only bias the analysis.

\section{Value Streams}

This section highlights the major value streams enabled or enhanced by microgrid functionality, as identified through a review of existing literature. These include both current and mature value streams as well as those that are projected to emerge as microgrids become a more common feature within the broader electricity grid. Table 1 outlines these value streams with details provided in subsequent sections. 
Table 1 - Summary of microgrid value streams

\begin{tabular}{|l|l|}
\hline Value Stream & Description \\
\hline Demand Response & $\begin{array}{l}\text { The local control over load and DER output within a microgrid makes it well } \\
\text { suited for demand response participation, wherein the microgrid responds to } \\
\text { instructions or incentives from a utility (or other entity) to reduce net } \\
\text { consumption and provide support to the broader electricity grid. }\end{array}$ \\
\hline Electricity Export & $\begin{array}{l}\text { Electricity generated within a microgrid can be exported to the electricity grid } \\
\text { under a variety of agreements with utilities. The overall value of exports is } \\
\text { highly situation dependent. }\end{array}$ \\
\hline Outage Resiliency & $\begin{array}{l}\text { On-site generation and storage resources create redundancy and back-up power } \\
\text { to mitigate economic losses due to unserved loads in the event of planned and } \\
\text { unplanned outages in the electricity grid. }\end{array}$ \\
\hline Local Energy Markets & $\begin{array}{l}\text { Local energy markets emerge when microgrids become sufficiently common to } \\
\text { interact with one another. By trading between microgrids, local markets may } \\
\text { create more favorable conditions for distributed renewable generation } \\
\text { increasing value for microgrid owners. }\end{array}$ \\
\hline
\end{tabular}

\subsection{Demand Response}

Demand response (DR) can be defined as changes in electric usage by end-use consumers from their normal consumption patterns in response to changes in the price of electricity over time, or to incentive payments designed to induce lower electricity use at times of high wholesale market prices or when system reliability is jeopardized [25]. Essentially, this can be done by reducing energy consumption through load curtailment strategies such as peak shaving, or by shifting energy consumption to different time periods, both achievable by either altering end-use loads directly or by taking advantage of onsite generation and storage resources [26]. Given their DER and control infrastructure, microgrids are well suited for DR participation.

\subsubsection{Price-based programs}

Existing demand response programs can be classified according to the distinction between Incentive or Event-Based (or Dispatchable), and Price-based programs (Non Dispatchable) [25]-[27].

Price-based DR programs feature time-varying electricity rates to motivate customers to adjust their consumption patterns that aim at flattening the demand curve by offering higher price during peak periods and lower prices during off-peak periods. Such programs include Time-of-Use (TOU) rates, Critical Peak Pricing (CPP) and Real Time Pricing (RTP). TOU rates vary by daily periods (typically including offpeak, shoulder, and peak hours) with fixed predetermined prices. CPP rates include a pre-specified extrahigh rate for peak hours that is triggered by the utility. RTP rates vary continuously during the day reflecting the wholesale price of electricity. In this case, participants are informed of the prices on dayahead or hour-ahead basis. Price-based programs are distinct from the participation in incentive or eventbased DR programs in the sense that there is no direct request for DR from the utility.

One of the key economic benefits available to microgrids is participation in price-based DR programs, given the microgrid's ability to control electricity imports using on-site generation and storage resources. 
The economic impact of this value stream can be particularly high in scenarios where utility TOU rates consist of both volumetric and power charges. Such tariffs are typically very strong incentives to enable both load leveling and peak shaving, as illustrated in Figure 1. In this case, an optimized load profile would theoretically be capped by a dynamic maximum demand level that follows the different time-ofuse periods established in the utility tariff. This would minimize both volumetric and power demand charges.

Microgrid deployments with multiple generation or storage resources can be highly effective at capturing peak shaving and load leveling value streams, which enhance their overall economic performance and viability.

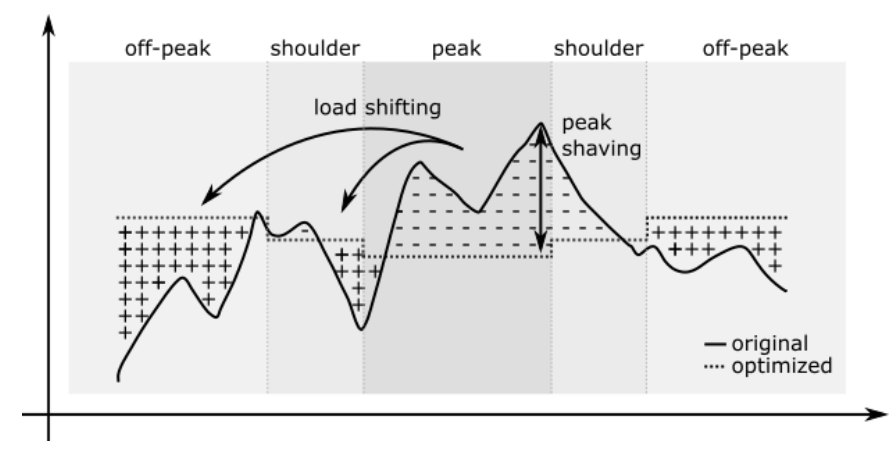

Figure 1 - Load shifting and peak shaving under time-of-use rates

The literature available on the economic analysis of load leveling and peak shaving benefits can generically be divided in two categories, depending on whether on-site generation is considered or not. Because battery energy storage systems alone can be operated in order to capture both of these revenue streams [28], it is often the case that methods are developed specifically for battery energy storage systems, and examples can be found in applications ranging from residential to large industrial microgrid scales.

The survey conducted on methods for the economic analysis of peak shaving and load shifting suggests a process where a demand limit is set and a battery energy storage system control algorithm is used to charge and discharge the storage systems depending on the availability of generation resources and demand levels in the calculation step. The definition of demand limits is subject to different approaches and control algorithms of different detail levels can also be found.

Namely, a method to assess the peak shaving potential of battery storage systems in the residential sector is presented in [29], and results show up to 50\% peak load reductions when sizing batteries to offset a demand limit target set to the highest $1.5 \%$ of electric loads. The suggested method consists of simulating different battery capacities and charging cycles to minimize costs by setting demand limits as a soft constraint. While the economic feasibility is not directly considered in this study, a similar methodology to analyze the economic benefit of batteries is used in [30] and [31], where separate load-shifting and peak-shaving oriented algorithms are presented. A wide number of battery technologies are analyzed, and the suggested economic returns represent up to $39 \%$ or $48 \%$ of the annual household electricity cost depending on the exact control strategy, tariff, and battery technology used. In these studies, however, the definition of the demand limit target is endogenous to the method, as it is determined from the tradeoff between the cost of additional battery capacity and failing to meet the demand limit target. 
Analyzing larger industrial microgrid applications, a method is presented in [32] to find the optimal battery energy storage system size while taking into account the economic benefit of peak shaving. The authors propose the use of a control algorithm based in dynamic programming to dispatch batteries of different sizes, constrained by preventing loads from exceeding a demand limit set arbitrarily. Battery energy storage systems were found to be cost effective, and up to $8 \%$ economic savings were realized from the different cases analyzed.

Despite the large economic potential for battery energy storage systems to provide load leveling and peak shaving, literature suggests that this is highly dependent on local settings, as it is made clear in [33]. In this study, the time-of-use tariffs contain only a volumetric component, and it is shown that economic viability of battery energy storage systems for load leveling and peak shaving is highly dependent of additional economic policy incentives, given that no TOU power demand charges are considered.

Alternative methods to account for the economic benefit of peak shaving and load leveling can be found in the form of large scale optimization models, where MILP models are most commonly found. In the work presented in [34]-[36] a large MILP model (DER-CAM) is used to dynamically schedule on-site generation and storage resources both deterministically and using stochastic methods. Results suggest potential savings of up to $28 \%$ of monthly utility bills. These studies focus on microgrid scenarios where photovoltaic panels, fuel cell units and BESS are present, and unlike the methods mentioned above, a preestablished demand limit target is not required as this limit is a direct result of the optimization process and is dynamically determined according to the utility tariffs and the minimization of total energy costs.

It can be concluded from the available literature that while technically load leveling and peak shaving may easily be attainable through the coordination of on-site generation and storage resources, the economic potential varies greatly with the applicable utility tariffs, site loads, and available resources, with a greater suggested potential in applications where peak to base load ratios are higher.

\subsubsection{Event-based programs}

Incentive or Event-based DR programs reward customers for reducing their electric loads upon request, or for giving the program administrator some level of control over the customer's electricity-using equipment. Examples include Emergency Demand Response Programs (EDRP), Capacity Market Programs (CM), Directly Controllable Loads (DLC), Interruptible/Curtailable rates (I/C), or Ancillary services (AS) and Demand bidding/buyback programs. In EDRP, customers receive incentive payments for load reductions when there is a need to ensure reliability of the power system, typically at peak times when demand can exceed supply. Customers who enroll in DLC and I/C programs are offered some incentives in exchange of the reduction of their loads to some pre-defined values. An example of I/C program is Pacific Gas \& Electricity (PG\&E) Base Interruptible Program [37] in which medium to large businesses receive a monthly incentive starting at $\$ 8 / \mathrm{kW}$ for reducing their load by a pre-selected 'Potential Load Reduction' upon 30 minutes advance notice. Failure to curtail load is penalized by a $\$ 6 / \mathrm{kWh}$ charge of uncurtailed energy. In case of DLC, the utility has direct control over some of the customers' electric appliances such as heating, ventilating, and air conditioners (HVACs). For instance, PG\&E SmartAC program for residential customers pays a $\$ 50$ incentive for residents who allow the utility provider some control over their air conditioners during summer high peak days [38]. AS programs reward customers with payments for committing to curtail load when needed to support operation of the grids (e.g. voltage and frequency control). Customers participating in Demand Reduction Bid Programs bid load reductions in wholesale electricity markets. For example customers enrolled in the PG\&E Demand Bidding Program receive a $\$ 0.50 / \mathrm{kWh}$ incentive for a load reduction bid after a day-ahead notice 
from the utility [39]. Microgrids are ideal candidates for such DR programs, due to their potential to enable participation in DR programs without service interruption, provided on-site generation and storage resources are leveraged on.

\subsubsection{Economic benefits of demand response}

DR has been widely lauded in the literature for its potential to increase power system flexibility and reliability, allowing a more efficient use of system assets and resources [40]. These benefits occur both directly to utilities and DR participants and indirectly to the broader customer base.

\section{Direct benefits}

From a utility perspective, DR can increase short-term capacity using market-based programs which result in avoided or deferred capacity costs [41]. Indeed, by flattening the demand curve, DR reduces high peak-hour capacity demand and therefore avoids significant costs associated with additional peak capacity requirements, both operating and investment costs. This contributes to important savings as peaking devices are usually flexible but expensive and inefficient conventional technologies such as open cycle gas turbine units [40]. An additional benefit from demand response may include reduction of greenhouse gas emissions released by such peaking generation. Furthermore, in the extreme case of generation or distribution outage risk, short-notice Emergency Demand Response Programs can help return to precontingency levels by reducing electricity demand, and therefore, avoiding potential costs associated to high-priority unserved loads, which can be defined through concepts like the Value of Lost Load [42].

Furthermore, by making the demand more flexible and facilitating balance of supply and demand, DR reduces costs associated to capacity reserves. A central benefit of many load types is that their power consumption can be adjusted instantaneously, allowing a much larger effective ramping rate from the aggregate DR resource than what can be achieved by larger generating plants. By supplanting slow or inefficient generation with flexible, responsive and inexpensive DR resources, microgrid-enabled DR reduces both the costs associated to operating generating plant at part load and cycling costs [40]. By decreasing the costs of capacity reserves DR facilitates the increased penetration of renewable energy resources, which typically additional spinning and standing reserve generation due to their intermittency. In [43], an optimal integrated market participation model of wind and PV energy including DR, storage devices, and dispatchable distributed generations in microgrids is presented. A stochastic programming approach is considered to propose bidding strategies for microgrids producers and loads. In a six days simulation of the model, it is shown that the total profits are increased by an average of $7.7 \%$ when considering demand bidding, made possible by the added microgrid flexibility. In [42], a stochastic energy and reserve scheduling method for a microgrid which considers various type of DR programs is proposed. All types of customers and three types of DR programs are considered: demand reduction bidding, ancillary services market programs, and Directly Controllable Loads. The uncertainties related to renewable distributed generation are modeled by probability distribution functions. The results of simulations show that the participation in DR programs enabled by the microgrid reduced the operating costs by $8.6 \%$. In [44] an economic evaluation of a microgrid supplied by a gasification power plant, operating in islanded mode and in comparison with other generation technologies is performed. DR is considered by integrating a demand bidding program similar to three current standard programs in the USA. The study concludes that using DR resources to balance the generation of the biomass power plant and the consumption within a microgrid is much more profitable than producing this energy by conventional technologies using fossil fuels: the avoided cost for the system is calculated to be $33.1 \%$ or $43.9 \%$ depending on the on-site generation technology used. 
It is worth noticing that, unlike in a standard power system where only commercial and industrial customers participate in demand bidding, in a microgrid paradigm even if the generation and demand levels are relatively low, the potential for residential consumers to participate in the market bidding is still high [45].

In [46] and [47] two examples can be found for microgrid participation in ancillary services for frequency and voltage control. They are a good alternative from using costly conventional power plant or storage devices. Specifically, in [46] a comprehensive central DR algorithm entitled Central Direct Load control is presented, based on an adaptive hill climbing strategy. Results indicate the ability to regulate the system frequency and voltage in an islanded microgrid, while minimizing the amount of manipulated responsive loads needed to keep the frequency within the desired range. More recently, a new framework for the coordination of distributed energy resources and DR for voltage and frequency support for islanded microgrids is presented in [47]. The loads are classified in controllable and non-controllable, and the process is formulated as a multi-objective problem solved by particle swarm optimization. Results show that the proposed control strategy can employ DERs and DR to effectively support the voltage and frequency of the islanded microgrids for different generation and consumption patterns. Furthermore, a new method is developed in [48] to improve a microgrid resilience in the moment subsequent to unplanned islanding. The microgrid features distributed energy resources, energy storage and electric vehicles, and a DR strategy consisting of curtailing pre-defined low-priority loads to ensure the microgrid stability in terms of energy balance and frequency control while minimizing the amount of load curtailed by taking into account the available on-site resources. This method was proven effective for short periods of islanding.

Looking into the potential of small resource aggregation in microgrids, [49] addresses the use of data centers and electric vehicle (EV) aggregators as demand-response resources, and a new model for the operation of a microgrid that includes distributed generation (DG) units, EV fleets and the data center's storage systems is proposed. In this example, the use of two distinct electricity storage technologies are considered to minimize energy costs by optimally charging or discharging according to the variations of electricity price from the grid and power output from the PV panels. The effectiveness of the proposed non-linear constrained optimization model was demonstrated by means of numerical applications.

In [50] the authors present a simulation-based optimization approach for the design of an Energy Management System in grid-connected photovoltaic-equipped microgrids with heterogeneous occupancy schedule. This EMS optimizes aggregated multi-objective criteria that take into account both the energy cost and the thermal comfort of the occupants of the microgrid, modelled with Fanger's concept of Predicted Percentage of Dissatisfied People. The proposed algorithm, the Parameterized Cognitive Adaptive Optimization, intelligently and automatically changes the energy demand of each building's Directly Controllable Loads (in this case HVAC) according to the electricity supply and the occupants' behaviour. Here, it is interesting to see that the Value of Lost Load is modelled by the occupants' discomfort as an added term of the optimization cost function.

\section{Indirect economic benefits}

The widespread participation of responsive demand resources in power markets has the potential to generate systemic economic benefits [26], [40], [41]. By reducing on-peak demand, and consequently from the avoided use of expensive peaking units, microgrid-enabled DR resources can contribute to 
reduce average wholesale prices, as well as the volatility of peak prices. This provides benefits to customers regardless of their participation in DR programs or microgrid status.

While literature suggests that the individual benefits of participating in DR programs are highly dependent on the specific customer, it is also suggested that even when looking only at the residential sector, societal benefits, as reduced costs, can be achieved [40], [51], [52].

It is worth mentioning that incentive-based programs are also beneficial to utility companies as the price paid to customers participating in the different DR programs is lower than the cost of generating additional power to supply the load [44].

\subsection{Power Exports and Net Metering}

Along with the participation in different types of DR programs, one of the most promising sources of revenue from the implementation of microgrids is the export of power back to the utility grid. There are several methods for determining the value of excess power generation from a microgrid, including net metering and feed-in tariffs. Net metering is the use of a bidirectional meter to measure a customer's net energy consumption over the span of a billing period. If on-site generation exceeds consumption, the meter runs backward. With feed-in tariffs (FIT), a payment is received for all electricity generated and injected back into the main grid. Both net metering and feed-in tariffs are highly dependent on local incentives, and are typically subject to specific eligibility rules.

Both net metering and feed-in methods have seen varying success in different regions on a national and global level. For example, while net metering is commonly found in the USA due to a favorable regulatory environment, FIT have been very successful in Germany due to strong support from the German government. Both mechanisms provide a simple way to monetize the investment made for onsite generation equipment, while providing valuable support to the grid and generally promoting the dissemination of more efficient and renewable technologies. However, these varying regulatory structures along with other drivers, prevent comprehensive quantification of the benefits of power export programs, resulting in highly situation-based evaluations. While the existing literature, such as [53], [54], [55], suggests that net metering is the most popular and simplest method for microgrids, a method for determining whether net metering or the feed in tariff is the most beneficial one in terms of social welfare and electricity rates is presented in [54]. Using a simple microeconomic model, the study concludes that the most favorable feature for social welfare is the adoption of net metering, provided there is a significant reduction in the measured consumption, or FIT when this is not the case.

While literature looking directly at the pricing of microgrid power exports is limited, [55] analyzes the use of feed-in tariffs and net metering for microgrids. Since net metering programs are primarily focused on incentivizing customers to conserve net energy usage, they often neglect effective management of the energy supplied back to the grid. Further, it is suggested that current tariff schemes could easily be applied to microgrids containing only renewable energy sources; however, those containing nonrenewable sources such as CHP may require an adaption of both net metering and FIT.

A case study presented in [53] looks at the impact of PV systems and legislation on the renewable energy sector. While this case study highlights some of the benefits through using net metering, it also shows that net metering is not the best economic option as increased liberalization of the renewable energy sector and a lack of significant government subsidies may dramatically decrease the impact net metering has. 
While net metering has been mostly used for PV, recent changes in public policy and improved technological improvements have increased the viability and usage of fuel cell based micro-CHP systems. The case studies in [56] analyze different policy frameworks for residential fuel cell power exportation such as ownership structures and promotion schemes using the cases of Denmark, France, and Portugal. Through the use of a cash flow model and technological simulations, the study concludes that the overall support levels are comparable to other systems such as PV, though the high operating and stack replacement costs decrease the immediate attractiveness of fuel cell systems. In Demark, where energy consumption is high and has high consumer prices, installing micro-CHP technologies with the use of a net metering pricing structure would be a promising solution as seen by the $30 \%$ reduction in gas prices and $17-55 \%$ decrease in net consumption. In contrast, in France and Portugal, the use of a virtual power plant on a day-ahead market, in which the fuel cell takes only electricity prices into account, is considered more attractive due to fairly low consumer electricity prices. While support mechanisms vary due to different policy structures, fuel cell systems can still provide a significant benefit to residential households with regards to energy usage. The study supports the idea that the concept of net metering can be applied outside of the traditional renewable energy sources successfully, making it particularly relevant in microgrid settings where multiple on-site generation technologies may be available.

Despites the benefits of net metering, it is not without problems. Utilities often oppose net metering and DG due to drastic decreases in income; resulting in increased cross subsidies paid for by non-DG owners when operators raise network prices. Alternative options such as capacity charging or fixed charging, only offer partial and inefficient solutions to this problem and still do not address one of the inherent issues with volumetric pricing, where the simplistic pricing structure may be sufficiently effective in mitigating disparities between electricity demand and real-time grid constraints [57]. The latter study suggests the use of explicit incentives that support PV instead of the current implicit incentives. This method would eliminate the practice of "netting", thereby avoiding cross subsidization, a utility practice that raises prices on non DG owners in order to make up for profits loss through net metering. Due to the practices of rolling credit, where surplus energy is credited to the customer, non DG owners have to compensate for 7.8-20\% of network users assuming 20\% PV penetration. Furthermore, a tariff design that is capacity based instead of energy flow based would be more cost reflective and increase cost recovery for utilities. This demonstrates that while net metering is an effective promotional structure, it cannot be a permanent solution in determining pricing structures for distributed generation.

In order to achieve smarter distribution, microgrids can be coupled in order to achieve self-healing and improved reliability, as explained in [58]. Coupled microgrids increase grid autonomous features and smooth transitions between grid-connected and islanding modes allowing for dependable power exports and bringing significant value to the concept of microgrids. Although islanding is a crucial attraction for microgrids, currently, microgrids provide the most value through their connection into the larger utility grid. In order to address the planning needs and capability of microgrids, [59] utilizes a nonlinear optimization model to develop capability diagrams which represent the active and reactive power exchange capability between microgrids and the utility grid. These diagrams assist in planning and understanding the potential for DG capability and the possible extent of ancillary services to the external network.

Much of the above literature has demonstrated that although exporting power back into to the utility grid is a strong value and revenue source, there is no definitive answer as to how this should be accomplished. 
Due to various policy regulations and technical parameters, the method for pricing the power supplied to the grid needs further discussion.

\subsection{Increased Resiliency \& Value of Lost Load}

An often mentioned benefit that results from the deployment of microgrids is the added reliability and resilience to prolonged outages. Recent natural events such as hurricane Sandy on the East Coast of the United States have served to emphasize resiliency issues, and have ultimately led to the development of specific incentive packages, such as the NY PRIZE [60] introduced by the New York State Energy Research and Development Authority that promote increased resiliency through the deployment of microgrids.

These issues, however, pose the sensitive question of understanding the value of resiliency. While sites such as hospitals, military facilities, or water treatment plants may be equipped with high levels of redundancy and sophisticated backup and emergency generation systems, defining the economic criteria behind the design of such systems is often a challenge, and more so when considering sites where valuing the continuous supply of energy may be more difficult.

Microgrids can play a significant role in this aspect, as the addition of coordinated on-site generation and storage resources can, if adequately sized, be used both in normal operation and during emergency situations. Particularly, on-site generation capacity can be oversized beyond the cost-optimal capacity for continuous duty so that they can meet critical loads during outage periods, and in so doing take advantage of potential economies of scale that may be obtained.

In short, the local generation and control introduced to a site through microgrid deployment provide a valuable resource in eliminating or mitigating adverse effects of planned or unplanned service interruptions or interruptions due to disturbances in power quality. This reliability benefit is an important component to consider in the planning and operation of a microgrid, but quantifying it accurately can be difficult. Rather than quantifying the value directly, one can attempt to quantify the cost of outages as a proxy to assess the value of reliability.

One commonly used metric for this is value of lost load (VoLL) which estimates the cost to consumers per unit energy not delivered, or alternatively the price consumers would be willing to pay to avoid disruptions [61]. VoLL can stem from a number of costs depending on the nature of the consumer. For industrial and commercial consumers this can include lost production due to down time, additional costs due to ramping up/down, or lost goods. For residential consumers, VoLL costs originate from lost leisure time and loss of goods [62]. In addition to consumer type and the nature of their operations, many external factors will affect VoLL, including the timing and duration of outage, season, region or location, and whether or not advanced notice has been given. For instance, an outage during overnight hours will not have the same adverse impact in a residential context as one in the mid-evening.

As a consequence of this, VoLL will vary significantly between contexts. Determining VoLL can be difficult without adequate data to characterize a consumer's damage function [63]. Historically VoLL has been determined by a number of different methods including customer surveys, market analysis, and case studies, with each of these methods presenting unique shortcomings [62]. More recently, a number of novel analytical models for determining VoLL or other related metrics have been published including [63]-[66]. A number of studies also provide estimations for VoLL by sector. It is important to note the contexts of these studies, as VoLL will be influenced by the conditions of its local economy. For instance, the damage function due to lost leisure time can be related directly to effective hourly wages [67]. In any 
case it is important to note that VoLL will always be significantly higher than the price of the undelivered energy. In a 2006 study of the Netherlands, de Nooij et al [62] estimated an economy-wide average of $\$ 12.62$ per $\mathrm{kWh}$ (Note: all values presented in this section are in inflation-adjusted 2015 U.S. dollars.) The residential sector exhibited a VoLL of $\$ 24.19$ per kWh, while government and offices had a VoLL of \$49.41. These are mostly in line with VoLL estimates used by Costa and Matos [68] for residential, commercial, and industrial contexts in Europe $(2.21,51.62$, and $29.50 \$ / \mathrm{kWh}$, respectively). In an earlier study, residential VoLL is estimated to vary between $\$ 2-\$ 10$ per $\mathrm{kWh}$, while commercial VoLL varies between \$5-\$46 per kWh [69]. Given this high level of variability, a site-specific analysis is likely necessary to produce an accurate estimate of the reliability value of microgrid deployment in avoiding costs due to lost loads.

\subsection{Local Energy Markets}

As microgrids become more common throughout the utility grid, additional value streams enabled by local interactions become possible. For instance, instead of exporting power back to the utility grid, microgrids could trade with neighboring microgrids. Facilitating this type of exchange between microgrids requires the establishment of a special framework: local energy markets. A local energy market is an auction-based online platform that allows microgrids within a distribution network to trade energy with each other [70]. Depending on their current load profiles, microgrids submit either demand or supply bids. Based on these bids market prices are calculated and loads allocated according to a predefined algorithm. Many studies model electricity as the commodity traded [71]-[73], while only few explicitly refer to energy (electricity and heat) [74]. Local energy markets are an emerging topic, so research in this field is still at an early stage [71], [75].

The establishment of local energy markets could enable a number of value streams for their microgrid participants. First, local markets for microgrids might produce cost savings on electricity bills [76]. For instance, [77] shows that for stand-alone microgrids local markets can reduce power costs by almost 8.5\%. In [73] it is suggested that cost savings for a microgrid system consisting of nine homes and varying battery and PV capacity can be obtained. Second, local energy markets curb the market power of utilities, especially if local energy markets are implemented by privately owned microgrids. Third, local energy markets facilitate the integration of intermittent distributed renewable generation into the existing energy infrastructure [70]. They contribute to overall grid stability as they provide microgrids with a platform to coordinate load requirements locally. Fourth, local energy markets increase energy efficiency since energy is consumed close to generation and less energy lost on long transmission lines. Given the early state of research, the value of these benefits for microgrids has not yet been properly quantified. Additional theoretical and experimental investigations for real-world applications are required to gain better understanding on how local energy markets perform in different economic contexts (e.g. feed-intariffs vs. net metering).

\subsubsection{Auction-based market design}

Local energy markets are modeled using auction theory in multi-agent environments. Each auction consists of three consecutive procedures: bidding, clearing, and pricing. Clearing refers to market clearing which is attained in accordance to a pre-defined algorithm [72], [77]. Pricing refers to setting a price for each allocated load (e.g. $\$ / \mathrm{kWh}$ ). In wholesale electricity markets pricing programs include TOU rates, CPP and RTP schemes (see 3.1). Two common rules for pricing in auctions theory are uniform and discriminatory pricing [78]. The former uses a uniform price per load (market clearing price based on 
submitted bids), which in dynamic environments may change from market period to market period. Discriminatory pricing allows each bidder to sell or buy at his or her own price. The different pricing mechanisms have yet only seldom been compared in local markets but were studied in wholesale electricity markets. When applied to the Californian Power Exchange Electricity Market, uniform pricing has been found to result in lower cost for electricity purchases than discriminatory pricing [79], [80]. Discriminatory pricing appears to reduce price volatility, but to trigger collusion which then results in increased prices for electricity [77]. Previous studies of auction-based wholesale electricity markets provide insight for local markets since both share a similar structure. In auction-based wholesale markets generators bid to supply electricity and distributors bid to buy electricity at a range of prices. The market is cleared every few minutes and is subject to technical constraints (e.g. matching power generation to demand and power flow constraints). Electricity markets are known for day-ahead and real-time auctions. The length of a market period varies but is mostly modeled as an interval between 15 minutes and one hour. In day-ahead auctions participants submit bids based on forecasted prices and load profiles. Based on these bids, a day-ahead market clearing price is calculated. The real-time market complements the dayahead market, buffers volatility and allows generators that are available but have not been chosen in the day-ahead market with an opportunity to supply [81].

\subsubsection{Residential energy auctions}

A residential energy market is modeled by [70]. The authors develop an auction mechanism for a local reserve energy market. Reserve energy refers to energy that is provided to a household (microgrid) that experiences an unexpectedly high demand or unforeseen outage in DER. Using microgrids and local markets for the provision of reserve energy creates an opportunity to reduce cost and balances interruptions close to source. In [70] the market is designed for a residential area and accommodates special needs of non-expert producers such as private households with DER. Focus on energy auctions in residential areas is also found in [72], which considers soft budget constraints of consumers whilst developing a clearing algorithm using uniform pricing. In [73] it is shown that for residential solarpowered microgrids the expected profits differ for uniform and discriminatory pricing. Finally, [74] introduces a combinatorial double auction mechanism for the allocation and pricing of electricity and heat in microgrids.

\subsubsection{Decentralized control infrastructure}

Local energy markets are primarily modeled as multi-agent systems in a decentralized control infrastructure consisting of numerous local agents and one coordinating market agent [75], [76]. Each agent possesses responsibilities to attain individual objectives but has limited knowledge about the other agent's profiles and objectives [82]. Local agents control single devices and process information that is known to the microgrid's owner only, e.g. capacity and cost of DER output, load profiles, cost functions, status of storage. In [75] and [76] a hierarchically controlled microgrid is suggested, in which local agents are controlled by a central controller. The central controller optimizes the interplay of DER, consumption and storage in the microgrid but has no knowledge about other microgrid's profiles. In each market period they submit a price-per-load bid to the market agent. The market agent collects price-per-load bids of all participants, clears the market and prices according to a predefined algorithm [83]. A system as such can be found in [77], where the authors develop an energy management system for stand-alone microgrids that can reduce energy costs by almost $8.5 \%$. The system is primarily carried by two algorithms. The first one provides day-ahead power profiles based on wholesale energy prices, hourly forecasting for DG and 
expected load demand. Day-ahead profiles are later updated with real-time profiles. In each market period, generation units submit bids to the market agent stating either a price-per-load $(\$ / \mathrm{kWh})$ or load $(\mathrm{kWh})$ request (offer). The second algorithm in [77] describes the local energy market. For each market period, it calculates a market clearing price using wholesale electricity prices, the number of generation units, as well as the total power generated and demanded.

\section{Conclusion}

This paper presents a literature review on aspects relevant to the economic feasibility of microgrids. It presents an overview of the most relevant technical challenges required to establish a microgrid that may increase the economic burden to a point that might jeopardize successful deployment. These include islanding detection, relaying and protection, and power quality monitoring.

This is followed by a review of the most relevant revenue streams relevant to microgrids, including several forms of DR, participation in export markets, understanding the value of resilience, and local energy markets. The key microgrid value streams identified in this review are:

- Demand Response: DR participation represents a mature revenue opportunity for microgrids. Depending on the characteristics of its load and DER, a microgrid could participate in one of many DR programs available in its region.

- Power Exports: On-site generation creates an opportunity to export power back to the grid. The overall value of this depends highly on local market and regulatory conditions, including the presence of feed-in tariffs or net metering.

- Resilience against outages: Loss of load can create high costs for consumers; the value of mitigating these lost loads can be very valuable, depending on the nature of the operations occurring within the microgrid. Resiliency provided by the microgrid mitigates these potential high costs.

- Local Energy Markets: These markets create the potential for future revenue streams when microgrids become sufficiently common. Under such markets, microgrids trade energy amongst themselves, rather than interacting exclusively with the grid. Local markets have the potential to reduce cost and increase renewable penetration rates.

It can be concluded from the analyzed literature that significant economic returns can be achieved by the deployment of microgrids, in applications ranging from residential to commercial and large industrial. It is made clearer that the exact monetization strategy is highly dependent on the site-specific conditions, namely in terms of the applicable tariffs, but overall there is a significant economic potential, and considering all possible revenue streams may be fundamental in successfully enabling the widespread deployment of microgrids.

\section{Acknowledgment}

The authors would like to acknowledge the partial funding of this work by the Office of Electricity Delivery and Energy Reliability, Distributed Energy Program of the U.S. Department of Energy under Contract No. DE-AC02-05CH11231. 


\section{References}

[1] B. Lasseter, "Microgrids [distributed power generation]," Power Eng. Soc. Winter Meet. 2001. IEEE, vol. 1, no. C, pp. 146-149, 2001.

[2] C. Marnay, F. J. Robio, and a S. Siddiqui, "Shape of the microgrid," Power Eng. Soc. Winter Meet. 2001. IEEE, vol. 1, no. C, pp. 150-153 vol.1, 2001.

[3] Y. Xu, H. Li, and L. M. Tolbert, "Inverter-based microgrid control and stable islanding transition," 2012 IEEE Energy Convers. Congr. Expo. ECCE 2012, pp. 2374-2380, 2012.

[4] Z. Yang, J. Le, K. Liu, and W. Cai, "Preliminary study on the technical requirements of the grid-connected microgrid," in 4th International Conference on Electric Utility Deregulation and Restructuring and Power Technologies (DRPT), 2011, pp. 1656-1662.

[5] C. Li, C. Cao, Y. Cao, Y. Kuang, L. Zeng, and B. Fang, "A review of islanding detection methods for microgrid," Renew. Sustain. Energy Rev., vol. 35, pp. 211-220, 2014.

[6] A. Mehrizi-Sani and R. Iravani, "Potential-Function Based Control of a Microgrid in Islanded and Grid-Connected Modes," IEEE Trans. Power Syst., vol. 25, no. 4, pp. 1883-1891, 2010.

[7] O. Palizban, K. Kauhaniemi, and J. M. Guerrero, "Microgrids in active network management - part II: System operation, power quality and protection," Renew. Sustain. Energy Rev., vol. 36, pp. 440-451, 2014.

[8] C. Liang, M. E. Khodayar, and M. Shahidehpour, "Adaptive Protection System for Microgrids: Protection practices of a functional microgrid system,” IEEE Electrif. Mag., vol. 2, no. 1, pp. 66-80, 2014.

[9] W. K. A. Najy, H. H. Zeineldin, and W. L. Woon, "Optimal Protection Coordination for Microgrids With GridConnected and Islanded Capability,” IEEE Trans. Ind. Electron., vol. 60, no. 4, pp. 1668-1677, 2013.

[10] S. Parhizi, H. Lotfi, A. Khodaei, and S. Bahramirad, "State of the Art in Research on Microgrids: A Review," IEEE Access, vol. 3, pp. 890-925, 2015.

[11] S. Mirsaeidi, D. Mat Said, M. Wazir Mustafa, M. Hafiz Habibuddin, and K. Ghaffari, "Progress and problems in microgrid protection schemes," Renew. Sustain. Energy Rev., vol. 37, pp. 834-839, 2014.

[12] S. A. Gopalan, V. Sreeram, and H. H. C. Iu, "A review of coordination strategies and protection schemes for microgrids,” Renew. Sustain. Energy Rev., vol. 32, pp. 222-228, 2014.

[13] P. Basak, S. Chowdhury, S. Halder nee Dey, and S. P. Chowdhury, "A literature review on integration of distributed energy resources in the perspective of control, protection and stability of microgrid," Renew. Sustain. Energy Rev., vol. 16, no. 8, pp. 5545-5556, 2012.

[14] M. Savaghebi, A. Jalilian, J. C. Vasquez, and J. M. Guerrero, “Autonomous Voltage Unbalance Compensation in an Islanded Droop-Controlled Microgrid,” IEEE Trans. Ind. Electron., vol. 60, no. 4, pp. 1390-1402, 2013.

[15] "IEEE Application Guide for IEEE Std 1547, IEEE Standard for Interconnecting Distributed Resources with Electric Power Systems," IEEE Std 1547.2-2008. pp. 1-217, 2009.

[16] "IEEE Recommended Practice and Requirements for Harmonic Control in Electric Power Systems," IEEE Std 519-2014 (Revision IEEE Std 519-1992), pp. 1-29, 2014.

[17] Y. Ito, Y. Zhongqing, and H. Akagi, "DC microgrid based distribution power generation system," in The 4th International on Power Electronics and Motion Control Conference, 2004, vol. 3, pp. 1740-1745 Vol.3. 
[18] S. Chakraborty, M. D. Weiss, and M. G. Simoes, "Distributed Intelligent Energy Management System for a SinglePhase High-Frequency AC Microgrid,” IEEE Trans. Ind. Electron., vol. 54, no. 1, pp. 97-109, 2007.

[19] S. K. Khadem, M. Basu, and M. F. Conlon, "A review of parallel operation of active power filters in the distributed generation system," in 14th European Conference on Power Electronics and Applications (EPE), 2011, pp. 1-10.

[20] Y. W. Li, D. M. Vilathgamuwa, and P. C. Loh, "A grid-interfacing power quality compensator for three-phase threewire microgrid applications," in IEEE 35th Annual Power Electronics Specialists Conference, 2004, vol. 3, pp. 20112017 Vol.3.

[21] L. Yunwei, D. M. Vilathgamuwa, and L. Poh Chiang, "Microgrid power quality enhancement using a three-phase fourwire grid-interfacing compensator," IEEE Trans. Ind. Appl., vol. 41, no. 6, pp. 1707-1719, 2005.

[22] L. Tzung-Lin and C. Po-Tai, "Design of a New Cooperative Harmonic Filtering Strategy for Distributed Generation Interface Converters in an Islanding Network," IEEE Trans. Power Electron., vol. 22, no. 5, pp. 1919-1927, 2007.

[23] W. Geng, L. Yongdong, and Y. Xiaojie, "A novel control algorithm for cascade shunt active power filter," in IEEE 35th Annual Power Electronics Specialists Conference, 2004, vol. 1, pp. 771-775 Vol.1.

[24] M. Hojo, Y. Iwase, T. Funabashi, and Y. Ueda, "A method of three-phase balancing in microgrid by photovoltaic generation systems," in 13th Power Electronics and Motion Control Conference, 2008, pp. 2487-2491.

[25] F. Shariatzadeh, P. Mandal, and A. K. Srivastava, "Demand response for sustainable energy systems: A review , application and implementation strategy," Renew. Sustain. Energy Rev., vol. 45, pp. 343-350, 2015.

[27] J. Aghaei and M. I. Alizadeh, "Demand response in smart electricity grids equipped with renewable energy sources: A review," Renew. Sustain. Energy Rev., vol. 18, pp. 64-72, 2013.

[28] J. Cho, S. Jeong, and Y. Kim, "Commercial and research battery technologies for electrical energy storage applications," Prog. Energy Combust. Sci., vol. 48, pp. 84-101, 2015.

[29] J. Leadbetter and L. Swan, "Battery storage system for residential electricity peak demand shaving," Energy Build., vol. 55, pp. 685-692, 2012.

[30] M. Zheng, C. J. Meinrenken, and K. S. Lackner, "Agent-based model for electricity consumption and storage to evaluate economic viability of tariff arbitrage for residential sector demand response," Appl. Energy, vol. 126, pp. 297-306, 2014.

[31] M. Zheng, C. J. Meinrenken, and K. S. Lackner, "Smart households: Dispatch strategies and economic analysis of distributed energy storage for residential peak shaving," Appl. Energy, vol. 147, pp. 246-257, 2015.

[32] A. Oudalov, R. Cherkaoui, and A. Beguin, "Sizing and optimal operation of battery energy storage system for peak shaving application,” 2007 IEEE Lausanne POWERTECH, Proc., no. 1, pp. 621-625, 2007.

[33] I. Kantor, I. H. Rowlands, P. Parker, and B. Lazowski, "Economic feasibility of residential electricity storage systems in Ontario, Canada considering two policy scenarios," Energy Build., vol. 86, pp. 222-232, 2015.

[34] C. Marnay, N. Deforest, M. Stadler, C. Dierckxsens, G. Mendes, J. Lai, and G. Cardoso, “A Green Prison : Santa Rita Jail Creeps Towards Zero Net Energy ( ZNE ),” in ECEEE 2011 Summer Study, 2011, no. June.

[35] N. Deforest, M. Stadler, C. Marnay, and J. Donadee, "Microgrid Dispatch for Macrogrid Peak- Demand Mitigation," in 2012 ACEEE Summer Study on Energy Efficiency in Buildings, 2012. 
[36] G. Cardoso, M. Stadler, a. Siddiqui, C. Marnay, N. Deforest, a. Barbosa-Póvoa, and P. Ferrão, "Microgrid reliability modeling and battery scheduling using stochastic linear programming," Electr. Power Syst. Res., vol. 103, pp. 61-69, 2013.

[37] "Base Interruptible Program (BIP).” [Online]. Available: www.pge.com/bip. [Accessed: 01-Oct-2015].

[38] “SmartAC Program.” [Online]. Available: www.pge.com/smartac. [Accessed: 01-Oct-2015]

[39] “Demand Bidding Program.” [Online]. Available: www.pge.com/dbp. [Accessed: 01-Oct-2015].

[40] N. Oconnell, P. Pinson, H. Madsen, and M. Omalley, "Benefits and challenges of electrical demand response: A critical review," Renew. Sustain. Energy Rev., vol. 39, pp. 686-699, 2014.

[41] M. H. Albadi and E. F. El-Saadany, “A summary of demand response in electricity markets," Electr. Power Syst. Res., vol. 78, no. 11, pp. 1989-1996, 2008.

[42] A. Zakariazadeh, S. Jadid, and P. Siano, "Smart microgrid energy and reserve scheduling with demand response using stochastic optimization,” Int. J. Electr. Power Energy Syst., vol. 63, pp. 523-533, 2014.

[43] H. Shayeghi and B. Sobhani, "Integrated offering strategy for profit enhancement of distributed resources and demand response in microgrids considering system uncertainties," Energy Convers. Manag., vol. 87, pp. 765-777, 2014.

[44] L. Montuori, M. Alcázar-Ortega, C. Álvarez-Bel, and A. Domijan, "Integration of renewable energy in microgrids coordinated with demand response resources: Economic evaluation of a biomass gasification plant by Homer Simulator," Appl. Energy, vol. 132, pp. 15-22, 2014.

[45] N. Venkatesan, J. Solanki, and S. K. Solanki, "Market optimization for microgrid with demand response model," NAPS 2011 - 43rd North Am. Power Symp., 2011.

[46] S. a Pourmousavi and M. H. Nehrir, "Real-Time Central Demand Response for Primary Frequency Regulation in Microgrids,” IEEE Trans. Smart Grid, vol. 3, no. 4, pp. 1988-1996, 2012.

[47] M. Bayat, K. Sheshyekani, S. Member, and M. Hamzeh, "Coordination of Distributed Energy Resources and Demand Response for Voltage and Frequency Support of MV Microgrids,” pp. 1-11, 2015.

[48] C. Gouveia, J. Moreira, C. L. Moreira, and J. a. Pecas Lopes, "Coordinating storage and demand response for microgrid emergency operation,” IEEE Trans. Smart Grid, vol. 4, no. 4, pp. 1898-1908, 2013.

[49] D. Proto, F. Mottola, and G. Carpinelli, "Optimal scheduling of a microgrid with demand response resources," IET Gener. Transm. Distrib., vol. 8, no. 12, pp. 1891-1899, 2014.

[50] C. D. Korkas, S. Baldi, I. Michailidis, and E. B. Kosmatopoulos, "Intelligent energy and thermal comfort management in grid-connected microgrids with heterogeneous occupancy schedule," Appl. Energy, vol. 149, pp. 194-203, 2015.

[51] P. Bradley, M. Leach, and J. Torriti, "A review of the costs and benefits of demand response for electricity in the UK," Energy Policy, vol. 52, pp. 312-327, 2013.

[52] B. Dupont, K. Dietrich, C. De Jonghe, a. Ramos, and R. Belmans, "Impact of residential demand response on power system operation: A Belgian case study,” Appl. Energy, vol. 122, pp. 1-10, 2014.

[53] A. S. Bouazzi and M. Krarti, "Net metering and its impact on PV program in Tunisia," 3rd World Conf. onPhotovoltaic Energy Conversion, 2003. Proc., vol. 3, 2003.

[54] Y. Yamamoto, "Pricing electricity from residential photovoltaic systems: A comparison of feed-in tariffs, net metering, and net purchase and sale," Sol. Energy, vol. 86, no. 9, pp. 2678-2685, 2012. 
[55] T. E. Del Carpio-Huayllas, D. S. Ramos, and R. L. Vasquez-Arnez, "Feed-in and net metering tariffs: An assessment for their application on microgrid systems," Proc. 2012 6th IEEE/PES Transm. Distrib. Lat. Am. Conf. Expo. T D-LA 2012, vol. 900, pp. 1-6, 2012.

[56] L.-L. Pade and S. T. Schröder, "Fuel cell based micro-combined heat and power under different policy frameworks - An economic analysis," Energy Convers. Manag., vol. 66, pp. 295-303, 2013.

[57] C. Eid, J. Reneses Guillén, P. Frías Marín, and R. Hakvoort, "The economic effect of electricity net-metering with solar PV: Consequences for network cost recovery, cross subsidies and policy objectives," Energy Policy, vol. 75, pp. 244254, Dec. 2014.

[58] R. H. Lasseter, "Smart distribution: Coupled microgrids," in Proceedings of the IEEE, 2011, vol. 99, no. 6, pp. 10741082.

[59] a. V. Jayawardena, L. G. Meegahapola, D. a. Robinson, and S. Perera, "Microgrid capability diagram: A tool for optimal grid-tied operation," Renew. Energy, vol. 74, pp. 497-504, 2015.

[60] “NY PRIZE.” [Online]. Available: http://www.nyserda.ny.gov/All-Programs/Programs/NY-Prize.

[61] K. G. Willis and G. D. Garrod, “Electricity supply reliability,” Energy Policy, vol. 25, no. 1, pp. 97-103, 1997.

[62] M. de Nooij, C. Koopmans, and C. Bijvoet, "The value of supply security. The costs of power interruptions: Economic input for damage reduction and investment in networks," Energy Econ., vol. 29, no. 2, pp. 277-295, 2007.

[63] D. Coll-Mayor, J. Pardo, and M. Perez-Donsion, "Methodology based on the value of lost load for evaluating economical losses due to disturbances in the power quality," Energy Policy, vol. 50, pp. 407-418, 2012.

[64] R. F. Ghajar and R. Billinton, "Economic costs of power interruptions: A consistent model and methodology," Int. J. Electr. Power Energy Syst., vol. 28, no. 1, pp. 29-35, 2006.

[65] K. K. Kariuki and R. N. Allan, "Evaluation of reliability worth and value of lost load," IEE Proc. - Gener. Transm. Distrib., vol. 143, no. 2, p. 171, 1996.

[66] A. Ratha, E. Iggland, and G. Andersson, "Value of Lost Load: How much is supply security worth?," IEEE Power Energy Soc. Gen. Meet., 2013.

[67] G. S. Becker, “A Theory of the Allocation of Time,” Econ. J., vol. 75, no. 299, p. 493, Sep. 1965.

[68] P. M. Costa and M. a. Matos, "Economic analysis of microgrids including reliability aspects," 2006 9th Int. Conf. Probabilistic Methods Appl. to Power Syst. PMAPS, pp. 1-8, 2006.

[69] C.-K. Woo and R. L. Pupp, “Costs of service disruptions to electricity consumers,” Energy, vol. 17, no. 2, pp. 109-126, 1992.

[70] C. Rosen and R. Madlener, “An auction design for local reserve energy markets,” Decis. Support Syst., vol. 56, pp. 168179, 2013.

[71] Z. Alibhai, W. A. Gruver, D. B. Kotak, and D. Sabaz, "Distributed coordination of micro-grids using bilateral contracts," in Systems, Man and Cybernetics, 2004 IEEE International Conference on, 2004, vol. 2, pp. 1990-1995 vol.2.

[72] W. J. Burke and D. M. Auslander, "Residential electricity auction with uniform pricing and cost constraints," in North American Power Symposium (NAPS), 2009, 2009, pp. 1-6.

[73] I. Maity and S. Rao, "Simulation and Pricing Mechanism Analysis of a Solar-Powered Electrical Microgrid," Syst. Journal, IEEE, vol. 4, no. 3, pp. 275-284, Sep. 2010. 
[74] C. Block, D. Neumann, and C. Weinhardt, "A Market Mechanism for Energy Allocation in Micro-CHP Grids," in Hawaii International Conference on System Sciences, Proceedings of the 41st Annual, 2008, p. 172.

[75] N. D. Hatziargyriou, A. Dimeas, A. G. Tsikalakis, J. A. P. Lopes, G. Karniotakis, and J. Oyarzabal, "Management of microgrids in market environment," in Future Power Systems, 2005 International Conference on, 2005, p. 7 pp.-7.

[76] Y. S. Foo Eddy, H. B. Gooi, and S. X. Chen, "Multi-Agent System for Distributed Management of Microgrids," Power Syst. IEEE Trans., vol. 30, no. 1, pp. 24-34, Jan. 2015.

[77] M. Marzband, A. Sumper, A. Ruiz-Álvarez, J. L. Domínguez-García, and B. Tomoiaglu a, "Experimental evaluation of a real time energy management system for stand-alone microgrids in day-ahead markets," Appl. Energy, vol. 106, pp. 365-376, 2013.

[78] R. Wilson, “Auctions of shares,” Q. J. Econ., pp. 675-689, 1979.

[79] P. Cramton and S. Stoft, "Why We Need to Stick with Uniform-Price Auctions in Electricity Markets," Electr. J., vol. 20, no. 1, pp. 26-37, 2007.

[80] A. E. Kahn, P. C. Cramton, R. H. Porter, and R. D. Tabors, "Uniform Pricing or Pay-as-Bid Pricing: A Dilemma for California and Beyond," Electr. J., vol. 14, no. 6, pp. 70-79, 2001.

[81] A. K. Basu, T. K. Panigrahi, S. Chowdhury, S. P. Chowdhury, N. Chakraborty, A. Sinha, and Y. H. Song, "Key energy management issues of setting market clearing price (MCP) in micro-grid scenario," in Universities Power Engineering Conference, 2007. UPEC 2007. 42nd International, 2007, pp. 854-860.

[82] S. Russell and P. Norvig, Artificial intelligence: a modern approach, 2nd ed. Upper Saddle River, NJ, USA: Prentice Hall, 2003.

[83] R. Duan and G. Deconinck, "Agent coordination for supply and demand match in microgrids with auction mechanism," in Infrastructure Systems and Services: Building Networks for a Brighter Future (INFRA), 2008 First International Conference on, 2008, pp. 1-4. 